\title{
Attitude of Higher Secondary Students in Shillong towards Mathematics
}

\author{
R. Lamar \\ Asst. Professor, Dept. Of Mathematics, St. Mary's College, Shillong)
}

\begin{abstract}
The present study was undertaken to find out the Attitude of Higher Secondary Students towards Mathematics. The researcher selected 308 Higher Secondary Students from 5 Higher Secondary Schools in Shillong. The researcher used the "Attitude Towards Mathematics Scale developed by Gakhar S.C. and Rajni to collect the data from the students. Appropriate statistical techniques like percentage, Mean and S.D. were worked out to find the nature of score distribution of the data collected. The ' $t$ ' test was applied to find out the significance of difference between different male and female students.
\end{abstract}

\section{Introduction}

In the contemporary world, greater emphasis is being placed on industrial and technological development. As a result, students are being encouraged to take science-related subjects. One subject that cuts across all the sciences is mathematics. Today, mathematical methods pervade literally every field of human endeavour and play a fundamental role in the economic development of a country. There is a strong belief that when it comes to learning, the cognitive and emotional domains are interconnected. Actual mental accomplishment or achievement depends strongly on emotionally-driven endeavours such as motivation, effort and perseverance. In our march towards scientific and technological advancement, we need good performance at all levels of schooling.

In the field of mathematics education, research on attitude has been motivated by the belief that 'something called "attitude" plays a crucial role in learning mathematics' (Neale, 1969).Attitude towards mathematics plays a crucial role in the teaching and learning process of mathematics. It affects students' achievement in mathematics. The teaching method, the support of the structure of the school, the family and students' attitude towards school affect the attitude towards mathematics. Usually, the way that mathematics is presented in the class-room and perceived by students, even when teachers believe that they are presenting it in an authentic and context dependant way, stands to alienate many students from mathematics. (Barton, 2000; Furinghetti and Pekhonen, 2002). Researchers concluded that positive attitude towards mathematics leads students towards success in mathematics.

In a study conducted by Saha (2007) on Gender, Attitude to Mathematics, cognitive style and Achievement in Mathematics, it was revealed that all the three contributes to statistically significant difference in achievement in mathematics. Another research conducted by Thomas (2006) on a study to determine the Attitude towards Mathematics and achievement by combining co-operative learning strategies with instruction delivered using an Integrated Learning System (ILS) showed that students using on ILS for mathematics instruction performed better on standardised tests and were more positive towards math when they worked in co-operative groups than when they worked on the same individually. A study to determine the casual ordering between Attitude towards Mathematics and achievement in mathematics of secondary school students done by Xin Ma and Jianymin (2004) showed the achievement demonstrated casual predominance over attitude across the entire secondary school. Gender difference in this casual relationship was not found but elite status in mathematics moderated this casual relationship.

\section{Rationale of the Study}

Attitudes are a powerful source for motivating students. They are capable of helping students to make adjustments in his/her life. They also contribute to determine our pattern of life as well as our success and happiness. Attitudes are a great driving force in achieving the goals that an individual has set for one-self. The success of students also depends on the ability of the teacher to get along with the students. There are three types of attitude towards mathematics: (i) Those who always perform well will have a positive or favourable attitude towards Mathematics (ii) Those who never perform well may have a negative or unfavourable attitude towards Mathematics and (iii) Those who can perform well; but do not fare well actually may have an average attitude towards mathematics.

The students of the third category may have the general intelligence to do well, but due to some factors, they do not do well in mathematics. Special attention will help students of this category to bring out their 
abilities in full. If this is not done in schools, the society may have to lose eminent scholars in mathematics and great mathematicians. The influence of the teacher on the pupil is not confined to imparting of subject knowledge alone, but goes further to play a part in the total development of the child. The influence of the teacher has been studied on the attitude towards mathematics.

In the present curriculum every attempt in being made to include mathematics as an integral part of school education to develop the speed and accuracy in doing numerical problems, an ability for abstract, an ability of logical reasoning, an ability for spatial concepts and so on. Teachers and parents are concerned with the Low achievement of students in mathematics and a number of studies had looked into the causes of such poor performance. Attitude is really the disposition of an individual to learn and to develop some proficiency in some particular area. Actually it helps to acquire knowledge in a particular area and on the basis of interest the future performance of a child can be predicted. Students under the pressure of parents or teachers selecting a professional course will be a failure in that area without attitude in that field. Hence the researcher has taken up this study to find out the attitude of Higher Secondary Students towards Mathematics.

\section{Objectives}

1. To study the Attitude of Higher Secondary Students towards Mathematics.

2. To find out the Attitude of Male Higher Secondary Students towards Mathematics.

3. To examine the Attitude of Female Higher Secondary Students towards Mathematics.

4. To compare the Attitude of Male and Female Higher Secondary Students towards Mathematics.

\section{Hypothesis}

1. There is no significant difference between the Attitude of Male and Female Higher Secondary Students towards Mathematics.

(i) Method

\section{Methodology}

The Descriptive Method was used in the study.

(ii) Sample

Random Sampling technique was used to select the sample. The study was conducted on a sample of 308 Higher Secondary Students of schools in Shillong, of Class XII level, from the Science Stream having Mathematics as one of the subject. Out of these 98 were Males and 210 were Females.

(iii) Tool Used

The tool used for the present study was the "Attitude Towards Mathematics Scale developed by Gakhar S.C. and Rajni. This tool consists of eight components namely, wider applicability, development of skills, reasoning, objectivity, intellectual development, non-intellectual development, individual outlook, and universal outlook. This scale is comprised of 46 statements. It is a five point scale. The total of scores of all statements is the total score of Attitude towards Mathematics.

(iv) Procedure

The scale was administered to 308 Class XII Higher Secondary Students of the Science Stream. The students were asked to read the instructions very carefully before giving their responses. The researcher also requested them to respond to all the items. The responses of the students were then scored on the bases of the 5 point scores. The obtained data was tabulated and analysed.

\section{Analysis and Interpretation of Data}

The analysis of data was done on the sequence of the objectives stated above. After the analysis of the raw scores, students having high, average and low Attitude towards Mathematics were identified on the basis of the following table.

Table 1: Showing the Range of Scores for Each Category

\begin{tabular}{|l|l|l|}
\hline Sl no & Categories & Range of Scores \\
\hline 1 & High Attitude & 152 and above \\
\hline 2 & Average Attitude & 75 to 151 \\
\hline 3 & Low Attitude & Below 75 \\
\hline
\end{tabular}

Objective I: To study the Attitude of Higher Secondary Students towards Mathematics.

The following table shows the overall Attitude of Higher Secondary Students towards Mathematics. 
Table 2: Showing the Overall Attitude of Higher Secondary Students Towards Mathematics

\begin{tabular}{|l|l|l|l|l|}
\hline S1 no & Categories & Range of Scores & No of Students & $\%$ \\
\hline 1 & High Attitude & 152 and above & 291 & 94.48 \\
\hline 2 & Average Attitude & 75 to 151 & 16 & 5.19 \\
\hline 3 & Low Attitude & Below 75 & 1 & 0.32 \\
\hline
\end{tabular}

\section{Interpretation}

Table 2 above shows that there is not much of a variation in the Attitude of Higher Secondary Students towards Mathematics. $94.48 \%$ of the students had high attitude and $0.32 \%$ had low attitude; $5.19 \%$ of the students had average attitude. This shows that majority of students had high attitude towards mathematics.

Objective 2: To study the Attitude of Male Higher Secondary Students towards Mathematics.

The following table shows the Attitude of Male Higher Secondary Students towards Mathematics.

Table 2: Showing the Overall Attitude of Male Higher Secondary Students towards Mathematics

\begin{tabular}{|l|l|l|l|l|}
\hline Sl no & Categories & Range of Scores & No of Students & $\%$ \\
\hline 1 & High Attitude & 152 and above & 93 & 94.9 \\
\hline 2 & Average Attitude & 75 to 151 & 5 & 5.1 \\
\hline 3 & Low Attitude & Below 75 & 0 & 0 \\
\hline
\end{tabular}

\section{Interpretation}

Looking at table 2, it is seen that $94.90 \%$ of the Male Higher Secondary Students were having high attitude, whereas on $5.10 \%$ of the Male Higher Secondary Students were having average attitude. The finding also reveals that none of the males were having low attitude towards mathematics. This indicates a healthy trend.

Objective 3: To study the Attitude of Female Higher Secondary Students towards Mathematics.

The following table shows the Attitude of Female Higher Secondary Students towards Mathematics.

Table 3: Showing the Overall Attitude of Female Higher Secondary Students towards Mathematics

\begin{tabular}{|l|l|l|l|l|}
\hline S1 no & Categories & Range of Scores & No of Students & $\%$ \\
\hline 1 & High Attitude & 152 and above & 198 & 94.29 \\
\hline 2 & Average Attitude & 75 to 151 & 11 & 5.24 \\
\hline 3 & Low Attitude & Below 75 & 1 & 0.47 \\
\hline
\end{tabular}

\section{Interpretation}

The overall attitude of Female Higher Secondary Students towards Mathematics shows a similar trend as the Male Higher Secondary Students towards Mathematics. 94.29\% were categorized under High Attitude, $5.24 \%$ were placed under Average Attitude and only $0.47 \%$ were having a Low Attitude.

Hypothesis 1: There is no significant difference between the Attitude of Male and Female Higher Secondary Students towards Mathematics.

The following table shows the significant difference between the Attitude of Male and Female Higher Secondary Students towards Mathematics.

Table 4: Showing the Differences between the Attitude of Male and Female Higher Secondary Students Towards Mathematics

\begin{tabular}{|c|c|c|c|c|c|c|}
\hline Group & $\mathrm{N}$ & Mean & SD & $\mathrm{df}$ & ' $\mathrm{t}$ ' & Inference \\
\hline Male & 98 & 178.67 & 19.52 & \multirow{3}{*}{306} & \multirow{3}{*}{0.59} & \multirow{3}{*}{$\begin{array}{l}\text { Insignificant } \\
\text { at } 0.05 \text { level }\end{array}$} \\
\hline Female & 210 & 177.29 & 17.82 & & & \\
\hline Total & 308 & & & & & \\
\hline
\end{tabular}

\section{Interpretation}

To verify the hypothesis, scores obtained by Male and Female Higher Secondary Students on Attitude towards Mathematics were entered in. The Mean Attitude Scores and S.D. of Male and Female Students were calculated and entered in the table above. Further the ' $t$ ' value was calculated to test the significance of difference between Mean Scores of Male and Female Students on Attitude towards Mathematics. The table reveals that there is no significant difference between the Male and Female Higher Secondary Students at 0.05 Level. Therefore the null hypothesis is retained.

\section{Findings and Conclusions}

On the basis of the analysis and interpretation of the data, the following conclusions were drawn.

There were no significant differences in the attitude of Higher Secondary Students towards Mathematics. Majority of the students had high attitude. This may be due to the fact that students are now aware 
of the importance of mathematics in the present day context. Further, the responsibility of teachers and parents to guide their children according to their attitude has improved to a great extend. Modern education must not restrict itself to developing more rote-learning, but also nurture the ability of students to produce relevant new meaning to their class-room experiences.

\section{Educational Implication}

Hence along with promoting educational achievement it is obligatory on the part of the school to equip students with the skill of logical thinking and reasoning which will enable him/her to cope effectively with whatever state of world they will encounter later in life. Curriculum which impacts training in these is the need of the hour.

\section{References}

[1] Farooq M.S and Shah S.Z.U (2008). "Students' attitude towards Mathematics". Pakistan Economic And Social Review, 75-83.

[2] Guimaraest, H. M. (2005) "Teachers and students views and attitude towards new mathematics curriculum". Journal of Educational Studies in Mathematics 26, 347-365.

[3] Kothari, D. S. (1966) (Chairman) Report of the Education Commission 1964-66. Government of India, New Delhi.

[4] Mishra S.K, Jain Sangeeta (2013). "Impact of Achievement Motivation, Gender and Locale on Achievement in Mathematics among Secondary School Students".Edutracks Vol.12 No.11

[5] Saha, S. (2007) "A study of Gender Attitude to Mathematics, Cognitive style and Achievement in mathematics". Experiments in Education 35, 6 .

[6] Thomas (2006) "The effects on student's achievements and attitudes using integrated learning systems with co-operative pairs". Journal Educational Technology Research and Development 45, 51-64.

[7] Xin Ma and Jiangmin Xu (2004) "Determining the causal ordering between attitude towards Mathematics and achievement in Mathematics". American Journal of Education110, 256-280.

[8] Zan Rosetta and Martino, Pietro D (2007). "Attitude towards Mathematics: Overcoming the Positive / Negative Dichotomy". The Montana Mathematics Enthusiast, ISSN 1551-3440, Monograph 3, pp.157- 168 2007@ The Montana Council of Teachers of Mathematics. 